\title{
Survival of Ascaris eggs and hygienic quality of human excreta in Vietnamese composting latrines
}

\author{
Peter KM Jensen*1, Pham D Phuc ${ }^{2}$, Flemming Konradsen ${ }^{1}$, Lise T Klank ${ }^{3}$ and \\ Anders Dalsgaard ${ }^{4}$
}

Address: ${ }^{1}$ Department of International Health, Immunology and Microbiology, Faculty of Health, University of Copenhagen, Øster Farimagsgade 5. PO Box 2099.1014, Copenhagen K, Denmark, ${ }^{2}$ National Institute of Hygiene and Epidemiology, Division of Enteric Infections, 1 Yersin Street, Hanoi, Vietnam, ${ }^{3}$ National Veterinary Institute, Technical University of Denmark, Bülowsvej 27, DK-1790, Copenhagen V, Denmark and ${ }^{4}$ Department of Veterinary Disease Biology, Faculty of Life Sciences, University of Copenhagen, Groennegaardsvej 15, DK-1870 Frederiksberg C, Denmark

Email: Peter KM Jensen* - petkj@sund.ku.dk; Pham D Phuc - pdphuc72@yahoo.com; Flemming Konradsen - fko@sund.ku.dk; Lise T Klank - ltj@vet.dtu.dk; Anders Dalsgaard - ad@life.ku.dk

* Corresponding author

Published: 16 December 2009

Environmental Health 2009, 8:57 doi:10.1 186/1476-069X-8-57

This article is available from: http://www.ehjournal.net/content/8/I/57

(c) 2009 Jensen et al; licensee BioMed Central Ltd.

This is an Open Access article distributed under the terms of the Creative Commons Attribution License (http://creativecommons.org/licenses/by/2.0), which permits unrestricted use, distribution, and reproduction in any medium, provided the original work is properly cited.

\begin{abstract}
Background: For centuries farmers in Vietnam have fertilized their fields with human excreta collected directly from their household latrines. Contrary to the official guideline of six-month storage, the households usually only store human excreta for three to four months before use, since this is the length of time that farmers have available to produce fertilizer between two cropping seasons. This study aimed to investigate whether hygienically safe fertilizer could be produced in the latrines within this period of time.
\end{abstract}

Methods: By inoculating eggs of the helminth parasite indicator Ascaris suum into heaps of human excreta, a die-off experiment was conducted under conditions similar to those commonly used in Vietnamese latrines. Half a ton of human excreta was divided into five heaps containing increasing concentrations of lime from $0 \%$ to $11 \%$.

Results: Regardless of the starting $\mathrm{pH}$, which varied from 9.4 to $1 \mathrm{I} .6$, a $>99 \%$ die-off of eggs was obtained after 105 to 117 days of storage for all lime concentrations and $97 \%$ of eggs were nonviable after 88 days of storage. The most critical parameter found to determine the die-off process was the amount of ammonia (urine) in the excreta which indicates that longer storage periods are needed for parasite egg die-off if urine is separated from the excreta.

Conclusion: By inactivating $>99 \%$ of all A. suum eggs in human excreta during a storage period of only three months the commonly used Double Vault Composting (DVC) latrine, in which urine is not separated, could therefore potentially provide a hygienic acceptable fertilizer.

\section{Background}

The World Health Organization (WHO) estimates that two billion people are infected with helminths globally. Even with this staggering number of helminth infections, it is often given low priority by health authorities as helminthiasis is not associated with high mortality. However, helminth infections do result in high morbidity, reduced growth among children, and negatively impacts 
the learning capabilities of school children [1-4]. In China alone, the number of people infected with Ascaris is estimated to be more than half a billon [5]. Considering the high prevalence in many Asian countries, helminth infections can have a considerable impact on the health and economy of rural households. This is especially pronounced in Vietnam where the prevalence of helminth infections exceeds $80 \%$ in some rural areas in its northern and central regions, possibly related to the widespread use of excreta as a fertilizer input in agriculture [3,6-10].

In many parts of Vietnam and southern China human excreta is not perceived as a hazardous waste but as a "valuable fertilizer" in agriculture. This century old tradition is deeply rooted and widespread in agriculture and even today farmers will go to great lengths to access and use excreta. Some sanitation projects in Vietnam have failed partly because the promoted latrines did not accommodate the use of excreta for agriculture; latrines were either forced open or broken into by farmers who sought access to the otherwise sealed off excreta[11].

To limit any negative health impact of excreta use, the Vietnamese Ministry of Health has issued guidelines recommending a minimum six month composting/retention time of excreta in a latrine before use $[9,12]$. For the widely promoted and commonly used Double Vault Composting (DVC) latrine, this implies that the full vault should be sealed off for at least six months while the other vault is used. However, in central Vietnam around $80 \%$ of the farmers do not seem to follow these guidelines, since their agricultural practices demand sowing and fertilization of new crops with excreta every three to four months [13]. In Vietnam, the rural population typically adds kitchen ash and, occasionally, lime to the latrine following a toilet visit, primarily to reduce the moisture content, prevent bad odour and to combat flies [10]. These practices are likely to increase the inactivation of parasite eggs and other pathogens since dry conditions and increased pH (lime) negatively affect pathogen survival [14-16].

Ascaris suum eggs from pigs can be used as a model for the survival of A. lumbricoides, the roundworm that commonly infects humans in less developed countries [17]. Helminth parasite eggs are widely used as hygiene indicators as they are more resistant to environmental stress compared with viral, bacterial and other parasite pathogens. In the present study, A. suum eggs were chosen as a hygiene indicator as they are easily obtained and are less infective to humans than A. lumbricoides, although they may still complete part of their life cycle in humans. Since the viability and environmental resistance of A. suum eggs are considered to be equal to those of A. lumbricoides eggs and greater than those of other helminth eggs, the survival of A. suum eggs has successfully been used as a suitable indicator organism for the survival of A. lumbricoides and other helminth eggs (Holmquist \& Stenström 2001). The aim of this study therefore was to use A. suum eggs to investigate whether the current practice of using of DVC latrines in Vietnam provides hygienically safe excreta fertilizer following a three to four month storage period. Furthermore, it was investigated whether lime applied in different quantities would increase $\mathrm{pH}$ and the parasite egg die-off and thus shorten the period required to produce hygienic excreta fertilizer.

\section{Methods}

Preparation of excreta for Ascaris egg survival experiments In May 2005, approximately $500 \mathrm{~kg}$ of human excreta was collected from single and double vault composting latrines used by 25 households in a village in peri-urban Hanoi. The collected excreta consisted of both fresh excreta and excreta that had been stored for three to four months, a situation similar to that in a double vault latrine before one vault is sealed off for composting. The households supplying the excreta had added ash to it on a regular basis but not lime; one third of the households used a urine separation toilet, whereas the remaining households both urinated and defecated in the same vault.

The excreta was transported to a closed household yard that was protected from rain by a plastic sheet. All the excreta was mixed manually for an hour by shovel and five heaps containing between $35-53 \mathrm{~kg}$ excreta were made. The homogenization of the excreta from the different latrines was to minimize any bias that could result from some families having added more ash following defecation than others. It was decided to carry out the experiment in heaps of excreta rather than directly in vaults as it was impractical to inoculate helminth eggs (see below) in the middle of a heap inside the vault in such a way that the individual bags with eggs could be removed for analyses without disturbing the remaining parasite egg bags. To obtain different alkaline conditions, four heaps were added with $1 \%, 3 \%, 6 \%$ or $11 \%$ hydrated lime w/w (mass lime per mass wet excreta) and one heap without lime (control). The excreta heaps were then inoculated with helminth eggs (Ascaris suum) and their survival studied to assess the hygienic quality of the composted excreta.

\section{Preparation and inoculation of Ascaris eggs}

Adult A. suum worms from the intestines of pigs were collected from a slaughterhouse in Hanoi city. The female worms were cut open and the last two centimetres of the bifurcation of the uterus, with mature eggs, was cut off. Pieces of the uterus were put in a test tube with tap water and a glass stick was used to press out the eggs from the uterus. The egg suspension was then passed through a sieve into another test tube to remove any large tissue frag- 
ments. The egg suspension was concentrated through centrifugation by $1000 \mathrm{rpm}$ for five minutes. The supernatant was withdrawn and the pellet re-suspended in $0.05 \mathrm{M}$ $\mathrm{H}_{2} \mathrm{SO}_{4}$ to suppress fungal and bacterial growth. A microscopic count (250-fold magnification) of 10 samples of $10 \mu \mathrm{l}$ was used to determine the egg concentration. This egg stock solution, which contained approximately $2.2 \times$ $10^{4} \mathrm{eggs} / \mathrm{ml}$, was stored in the refrigerator at $4-5^{\circ} \mathrm{C}$ up to three days before being inserted into the excreta heaps.

A rectangular piece $(45 \times 85 \mathrm{~mm})$ of polyamide cloth (Monodur PA 31.5 N. Verseidag-Techfab GmbH, GeldernWalbeck, Germany) with a pore-size of $20 \mu \mathrm{m}$ (the size of the eggs are $45-70 \times 35-50 \mu \mathrm{m}$ ) was used to produce the so-called tea bags that are widely used for helminth egg survival experiments [17]. Each bag contained approximately 20,000 A. suum eggs and a nylon fishing line was attached to allow for easy removal of the bags from the excreta heaps. The bags were kept in $0.1 \mathrm{M} \mathrm{H}_{2} \mathrm{SO}_{4}$ in a refrigerator for a day until brought to the field site and inserted into the heaps. The tea bags used for control samples were stored in $0.05 \mathrm{M} \mathrm{H}_{2} \mathrm{SO}_{4}$ in a refrigerator for up to six months.

Twenty four bags each with A. suum eggs were carefully placed in the centre of each of the five heaps. To capture biological variation and any impacts from variations in local environmental conditions inside the heap, two separate teabags were collected from each heap at each of the 12 sampling sessions. To further investigate the temperature effect on egg survival, four tea bags were placed in the top as well as in the bottom of the heap with no lime.

\section{Sampling and viability testing of Ascaris eggs}

After 30 days of storage, two tea bags from each heap were removed by gently pulling the attached string. Subsequent sampling of tea bags was done every two weeks from May to November 2005. In addition to the sampling of the teabags inserted in the middle of the heap, the tea bags placed in the top and bottom of the heap with no lime added were sampled at 30-days intervals.

Viability testing of eggs was done according to earlier described methods on the day the tea bags were collected [17]. The tea bags were washed gently by filling them with distilled water and shaken in a way that concentrated the eggs at the bottom of the bags. The tea bags were opened with a pair of scissors and placed in separate petri dishes containing $10 \mathrm{ml} 0.05 \mathrm{M} \mathrm{H}_{2} \mathrm{SO}_{4}$ with the fluid level marked on the side of the petri dish. Two petri dishes containing $0.05 \mathrm{M} \mathrm{H}_{2} \mathrm{SO}_{4}$ were prepared for each sampling time and kept as controls, with one dish containing free Ascaris suum eggs $\left(2.2 \times 10^{4} \mathrm{eggs} / \mathrm{ml}\right)$ and another dish containing a closed tea bag with eggs, to assess the survival of the eggs in the solution as well as any impact of the tea bag on egg survival. These controls were used to calculate the percentage of viable eggs. The eggs and the fluid level were checked twice a week and the lids were taken off the petri dishes for 15 minutes twice a week to allow for adequate aeration of the eggs. If the fluid level was too low, distilled water was added. The egg viability was determined by comparing the percentage of viable eggs from the control with those of the sample. The eggs were incubated at room temperature $\left(25-31^{\circ} \mathrm{C}\right)$ for four weeks before their survival were determined. By this time the viable eggs would have developed into larvae.

To determine the viability level of the eggs, i.e. whether a live larva had developed inside the eggs, they were carefully scraped, with a pipette, from the inside of the tea bags and placed in a drop of $0.05 \%$ methylene blue on a microscopy slide. A magnification of 10 and 45 times was used. The eggs were divided into three categories: those containing a dead larva (larva coloured blue), those containing a live larva and those that had not embryonated. Only whole eggs were counted. Viable eggs were defined as those containing a live larva. Where possible, a minimum of 100 eggs were counted and evaluated from each tea bag, thus no survivors counted would be equivalent to a $99 \%$ level of inactivation. If the eggs had not started to develop, only 20-30 eggs were counted in order to optimize the laboratory efficiency. The two teabags from each sampling heap were enumerated in parallel procedures and results were reported as the average of the two.

\section{Measurements of temperature}

Seven Tiny talk ${ }^{\circledast}$ temperature data loggers (Gemini Data Loggers (UK) Ltd. Chichester, United Kingdom.) in acidresistant plastic bags were placed in the middle of the five heaps of excreta. To measure the possible different temperatures inside the excreta heap one heap also had temperature loggers placed in the top and bottom. Another two loggers were placed in the house and a shed next to where the heaps were placed to monitor the outdoor temperatures. The loggers were set to measure and log the temperature every four hours. At the end of the five month experiment the loggers were taken out of the heaps and the data uploaded to a computer.

\section{Moisture content, $\mathrm{pH}$ and nitrogen measurements}

One cylinder ( $3 \mathrm{~cm}$ in diameter) of excreta sample was taken by driving a pipe down through the heap, as close to the centre as possible without hitting the tea bags. The sample was pushed out of the cylinder into a plastic bag and immediately transported to the National Institute of Soil and Fertilizer, Hanoi, for $\mathrm{pH}$ and moisture content analyses. Moisture content was measured on a monthly basis. Porcelain bowls were dried at $110^{\circ} \mathrm{C}$ in an oven for an hour, and weighed after cooling in a desiccator. Thereafter $10 \mathrm{~g}+/-1 \mathrm{~g}$ of sample was placed in the bowl and 
weighed again. The bowl was then placed in a drying oven at $105^{\circ} \mathrm{C} \pm 3{ }^{\circ} \mathrm{C}$ overnight, then positioned in desiccators for cooling and thereafter weighed.

$\mathrm{pH}$ was measured at day zero and once every two weeks by adding $10 \mathrm{~g}$ of sample excreta to $50 \mathrm{ml}$ of distilled water in a 100-ml glass beaker. The mixture was left to stand for 10 minutes and larger clumps of excreta were broken down manually with a glass rod. The suspension was then stirred for 10 minutes and thereafter a calibrated electrode (calibration at pH 7 and $\mathrm{pH} 10$ ) was inserted in the suspension for $\mathrm{pH}$ measurement [18].

During the sampling period the heaps were measured for nitrogen content. Monthly, the $\mathrm{pH}$ samples were also analyzed for the content of Kjeldahl nitrogen (organic) and only once for the content of total nitrogen, as in the procedure described in [19].

\section{Results}

The $99 \%$ die-off time for A. suum eggs exposed to the different alkaline conditions ranged from 105 to 117 days (Figure 1). The survival rate of eggs used as controls was $63-70 \%$ throughout the experiment, with no difference between the control eggs inside the bags and the ones placed in petri dishes (results not shown). When adjusted for counts of survived eggs in the control bags, a mean of $3 \%$ of the eggs placed in the five experimental excreta heaps were alive after 88 days (range $9-1 \%$ ), 1\% after 103 days (range $2-<1 \%$ ) and $<1 \%$ after 117 days of storage. Thus, similar overall die-off times were seen for eggs despite some initial differences in the die-off rates. This showed a slower die-off rate for the excreta heaps with $0 \%$ lime and a more rapid initial egg die-off for the heaps with the highest $\mathrm{pH}$. As seen in Figure 1, there was no difference in the die-off time between the heaps with high $\mathrm{pH}$ and those with a low $\mathrm{pH}$. Interestingly, it was seen that even though lime was added to the heaps to obtain increased alkaline conditions with initial $\mathrm{pH}$ values ranging between 9.4 to 11.6 , the variation in $\mathrm{pH}$ values after 133 days of storage narrowed to less than one $\mathrm{pH}$ unit ( $\mathrm{pH} 8.6-\mathrm{pH} 9.5)$. The survival rate of controls was 63$70 \%$ throughout the experiment, with no difference between the control eggs inside the bags and the ones placed in petri dishes (results not shown).

There was no difference in the total die-off time between eggs in the tea bags inserted in the top and bottom of the excreta heap with $0 \%$ lime. Eggs in bags placed in the top of the heap had a $27 \%$ survival after 75 days as against $26 \%$ of eggs placed in the bottom. After 88 days, these rates were $9 \%$ versus $7 \%$, respectively, with none of the

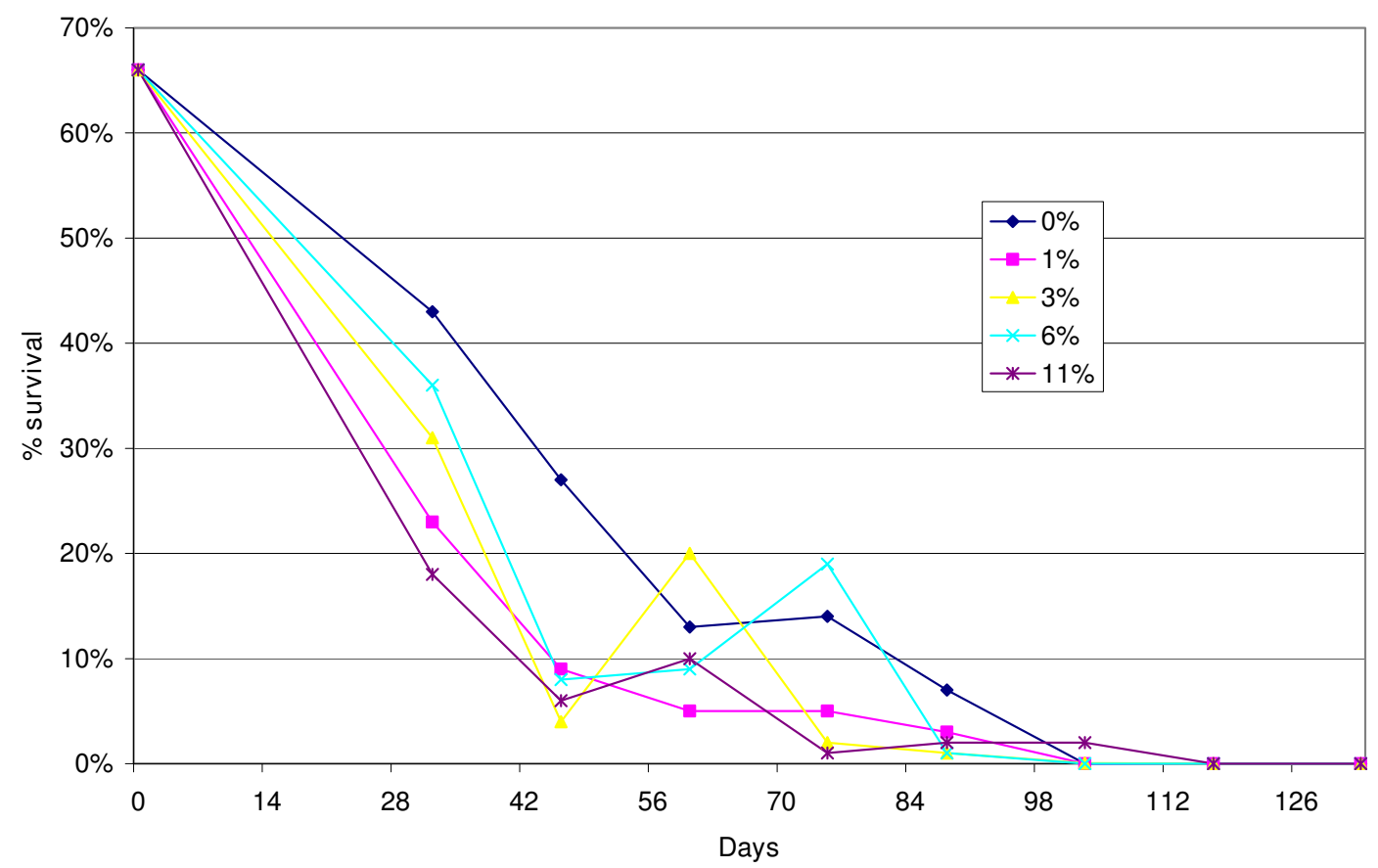

\section{Figure I}

The influence of storage time on survival of Ascaris suum eggs in heaps of human excreta under different alkaline conditions (\% lime). 
eggs placed at both locations found viable after 103 days. However, when the eggs in the top and bottom were compaired to the once placed in the middle a slower die-off rate was observed, in the middle a $27 \%$ survival was reached after only 46 days storage which was 30 days prior to the date when the same die-off was reached in the bottom and top samples. These result suggest that the die-off rates for the helminth eggs were not significantly increased by the elevated temperatures registered in the top of the heap, which reached a maximum of $50.4^{\circ} \mathrm{C}$, with simultaneous temperatures of $38.0^{\circ} \mathrm{C}$ in the middle and $35.3^{\circ} \mathrm{C}$ in the bottom of the heap (Figure 2).

Figure 2 shows the temperature development in the top versus the middle of the excreta heap and the ambient temperature as measured every four hours during the 120day duration of the experiment. Except for the initial three weeks, the temperature development in the heaps followed the same pattern of the ambient temperature measured with the outdoor temperature logger, suggesting that a very limited thermophilic composting took place during the experiment. During the first three weeks, the average temperature in the bottom of the heap was $4{ }^{\circ} \mathrm{C}$ higher than the average ambient temperature. Figure 2 shows large temperature variations inside the top of the heaps.
Over a 24-hour period during the summer months, a variation of up to $18^{\circ} \mathrm{C}$ degrees was recorded $\left(32-50^{\circ} \mathrm{C}\right)$ and in the cooler autumn months the variation was limited to $5-10^{\circ} \mathrm{C}$ with a minimum temperature of $26^{\circ} \mathrm{C}$.

There was an increase in moisture content, from between $40-50 \%$ to $60-70 \%$, in the heaps during the 120 days. That was most likely due to rainwater penetration of the tarpaulin used to cover the compost heaps.

The average concentration of total nitrogen in the heaps was $97 \mathrm{mg} \mathrm{N}$ per kg excreta. The results presented in Figure 3 shows low $\mathrm{pH}$ (low percentage of lime) concentrations in the beginning of the experiment, which correlates with high organic nitrogen $\left(\mathrm{NH}_{3}\right.$ and $\left.\mathrm{NH}_{4}{ }^{+}\right)$concentrations. In comparison, heaps with a high $\mathrm{pH}$ (high percentage of lime) showed rapid changes in the content of organic nitrogen. These rapid changes are illustrated in Figure 4 where all the different parameters $(\mathrm{pH}$, organic nitrogen, moisture and egg die-off) are listed for the heap with 3\% lime. A polynomial trend line is added for the organic nitrogen and moisture analyses, as these were not done as frequently as the analysis of egg survival.

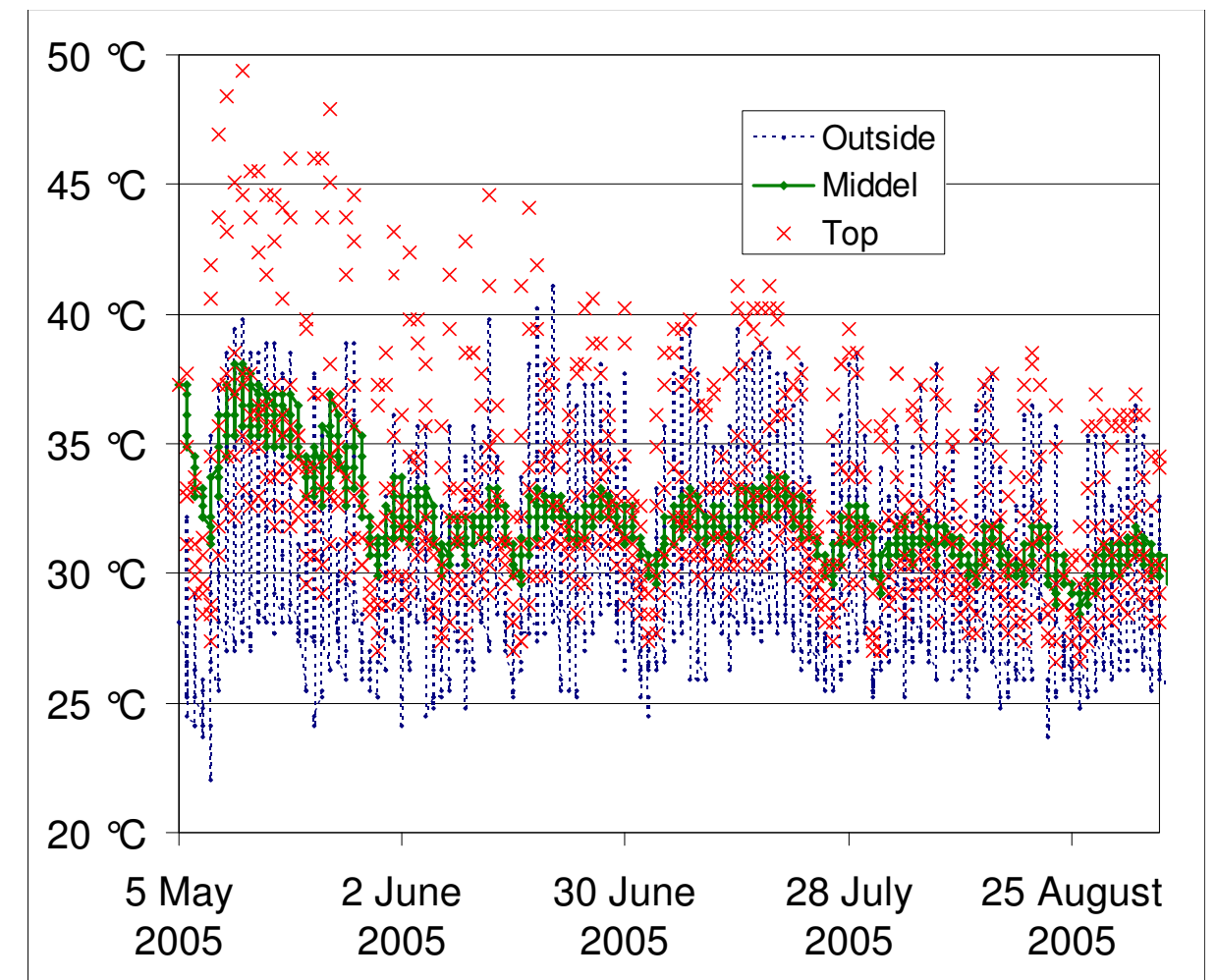

\section{Figure 2}

The Temperature development in the top and the bottom of the heap with no lime added, plot together with the ambient temperature. 


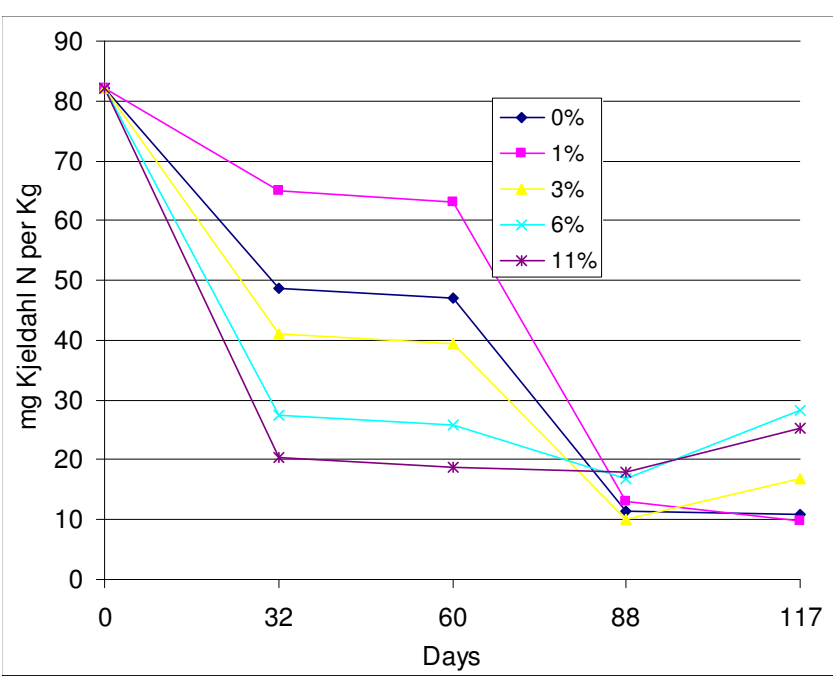

Figure 3

Temporal development of Kjeldahl nitrogen $\left(\mathrm{NH}_{3}\right.$ and $\mathrm{NH}_{4}{ }^{+}$) concentrations in excreta heaps with different lime content (\%).

\section{Discussion}

The main aim of this paper was to evaluate if the current practice of using Double Vault Composting (DVC) latrines in Vietnam provides hygienically safe excreta fertilizer following a three to four month storage period. When placing Ascaris suum eggs in heaps of human excreta with $\mathrm{pH}$ levels between 9.4-11.6, it took a maximum of 117 days to achieve a 99\% die-off of the eggs, irrespective of the initial $\mathrm{pH}$. This suggests that the Vietnamese farmers, through their normal storage and composting practices and under environmental conditions as described in this paper, could potentially produce hygienically safe human excreta for use as fertilizer in agriculture within the six month storage period stipulated in the national guidelines. Our findings also showed that the addition of lime at different concentrations to the excreta had a limited effect on $\mathrm{pH}$ development and egg survival. Previous research has also found a similar lack of correlation between the concentration of lime and Ascaris die-off in human excreta for $\mathrm{pH}$ below 12 [20]. However, other studies using sludge from waste water treatment plants report that the die-off time depends on $\mathrm{pH}$ and generally a $\mathrm{pH}>12$ is recommended to obtain safe sludge for use as fertilizer [20-22].

Temperature increases in the excreta heaps due to microbiological processes were only seen to a limited extent and only within the first three weeks of storage. Thus, temperatures in the heaps were determined mainly by the ambient temperatures. Our findings are in accordance with other studies that showed little, if any, temperature development during storage (Figure 2). However, there were large variations on both the daily and weekly average temperatures. If we had used the midday temperatures measured inside the top of the heaps to estimate the die-off times, our results on egg survival would have been seriously overestimated. As an illustration of the problem of overestimation of egg survival, an average temperature over a 7-day period measured at 2:00 pm in the top part of the excreta heap would result in an estimated average temperature of $47^{\circ} \mathrm{C}$, a temperature which according to the normal cited curve on Ascaris temperature versus dieoff time would result in a $100 \%$ die-off after only five to six days of storage [23]. In contrast a similar exercise in the bottom of the heap (an exercise which is difficult to carry out inside the latrine vault) would result in an estimated average temperature of $35^{\circ} \mathrm{C}$, which according to [23] gives a die-off time of more than a year. The increased temperatures in the top could be explained by a higher biological activity due to the supposed higher oxygen content close to the surface of the heap. However after examining the variation of the temperatures, it is more likely that the top data logger's proximity to the surface exposed it to the ambient temperatures. Therefore care must be taken when estimating the pathogen die-off time based on measured temperatures. To increase the safety margin in estimations of pathogen die-off time it is recommended that experiments use the night temperature as the daily average.

From the onset of the experiment, the die-off rate of $A$. suum eggs was highest in the heaps with the highest $\mathrm{pH}$ values. However, after approximately two months of storage this tendency disappeared and eggs in all heaps showed similar die-off rates until all eggs were found nonviable after 105 to 117 days. A similar trend was seen with the $\mathrm{pH}$ values with large variations in the beginning of the experiment of more than three $\mathrm{pH}$ units to variations of less than one $\mathrm{pH}$ unit after three months storage. Pecson et al. [22] also observed this "internal buffer" effect and argue that it is caused by ammonia volatilization with the ammonium ion, $\mathrm{NH}_{4}{ }^{+}$, being changed to ammonia, $\mathrm{NH}_{3}$, at alkaline conditions $\left(\mathrm{pK}_{\mathrm{a}}=9.3\right.$ at $\left.25^{\circ} \mathrm{C}\right)$. This could explain why we saw a large decrease in the organic nitrogen concentration as measured by the Kjeldahl $\mathrm{N}$ method $\left(\mathrm{NH}_{4}{ }^{+}\right.$plus $\left.\mathrm{NH}_{3}\right)$ in the heaps with high $\mathrm{pH}$ values (Figure $3)$. The ammonia created under such alkaline conditions would volatilize and therefore lead to a lower $\mathrm{pH}$. It does not seem to be the high $\mathrm{pH}$ itself that inactivates the Ascaris eggs, but the presence and negative impacts on egg survival of $\mathrm{NH}_{3}$ [22]. This could therefore explain why a fast die-off rate of eggs was seen in the beginning of the experiment in the heaps with the strongest decline in the content of organic nitrogen, i.e. free ammonia would have caused a kill-off effect before it volatilized. Our results further support this theory as illustrated by the individual heap where the curves for organic nitrogen, $\mathrm{pH}$ and Ascaris 
eggs die-off decreased simultaneously (Figure 4). The changes in the content of organic nitrogen had to be superimposed with a trend line to visualize the evaporation (Figure 4). Unfortunately we did not measure the Kjeldahl $\mathrm{N}$ before day 60 of the experiment. The concentration of $\mathrm{NH}_{3}$ and $\mathrm{NH}_{4}{ }^{+}$in our experiments was at maximum $82 \mathrm{mg} \mathrm{N}$ per kg excreta and to our surprise a similar effect was seen on egg survival when experiments were done with $\mathrm{NH}_{3}$ concentrations of $5000 \mathrm{mg} / \mathrm{l}$ in liquid sludge [22]. This demands further investigation under real-life conditions and concentrations of $\mathrm{NH}_{3}$, especially on how the rate of egg survival is affected during the first critical days/weeks of the contact between the eggs and $\mathrm{NH}_{3}$.

A. suum eggs are commonly used as a model organism for A. lumbricoides, the roundworm that often infect humans in less developed countries [24]. For survival and viability studies, eggs of A. suum are usually collected directly from the uterus of adult female worms. However, when excreted from the pig or human hosts, A. suum and A. lumbricoides eggs have been exposed to the gut environment and then to the external environment, i.e. in the pig sty and latrine. The maturation that the eggs undergo due to the exposure to the external environment is likely to make the eggs more resistant to environmental stress than eggs that have been removed directly from the uterus of adult female worms. Although it is preferable to use eggs for survival experiments that are recovered directly from faeces, this is rarely done because a heavy workload and a rela-

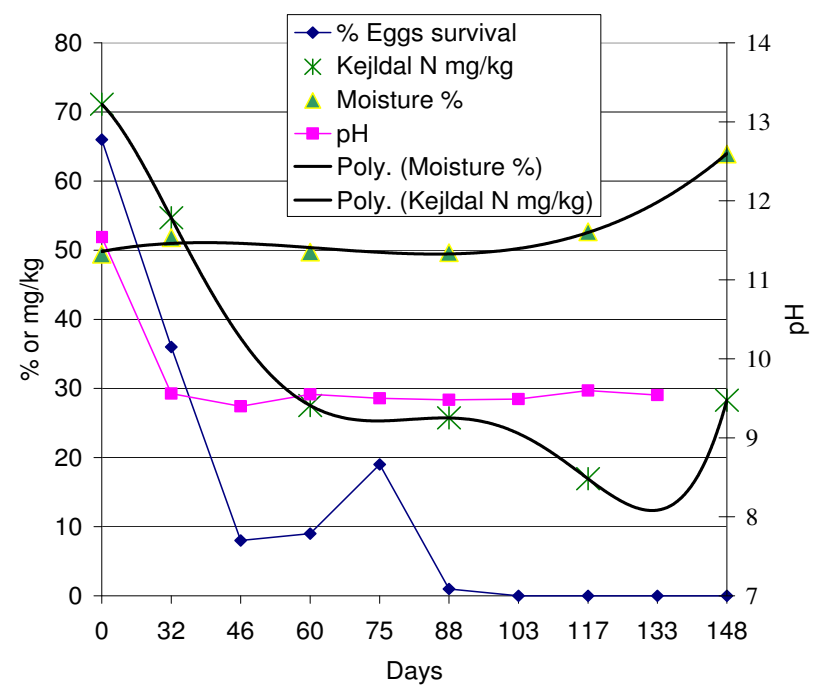

\section{Figure 4}

Changes in the physical, chemical, and microbiological parameters in the heap amended with $3 \%$ lime. A polynomial trend line is superimposed over the nitrogen and moisture measurements. tively low number of eggs are obtained compared with collecting eggs from adult female worms. Differences in the survival of eggs of different origin should be taken into consideration when evaluating and comparing results from studies on egg viability. As eggs collected from the uterus of adult worm were used in our study, it is likely that the viability of eggs was underestimated. There is an urgent need to establish how different development stages of eggs, their collection procedures, and their previous external environmental exposures impact the viability of A. suum eggs and its suitability as an indicator organism.

If our study results are evaluated on the basis of our previous findings, that a Vietnamese farmer would normally only store excreta for three to four months, which is the time period between the application of excreta-based fertilizers in the field [13], it is possible to estimate the rate of reduction of viable helminth eggs in human excreta used by farmers for crop fertilization. Presuppose that the vaults are used in three month intervals, i.e. three months for filling the vaults and three months storage under similar environmental conditions [13], and that there is a $97 \%$ die-off after three months and a $>99 \%$ egg die-off after four months storage as found in the present study. Then only stored excreta produced in the last month of filling the vault may contain viable eggs; and of these eggs more than $97 \%$ will no longer be viable. This suggests that an average non-urine separating DVC latrine would reduce the number of viable $A$. suum eggs by more than $99 \%$ of the initial concentration after just three months of storage. From a public health point of view, our results suggest that the application of excreta that has been stored in DVC latrines to fields might only play a minor role in the overall transmission of helminth infections in Vietnamese households in rural areas, and the major source for the high prevalence of helminth infections could be found elsewhere, like in small children's indiscriminate defecation pattern outside the latrines as we observed in the area. However, these findings apply only to non-urine separation latrines. If the urine is separated, which is also a common practise in Vietnam, then longer storage times are probably needed since the egg die-off will not benefit from the impact of $\mathrm{NH}_{3}$ and $\mathrm{NH}_{4}{ }^{+}$in the urine. Further studies are needed to document to what extend urine separation may increase the survival rate of helminth eggs in stored excreta.

In order to quantify the risk to the household using human excreta as fertilizer composted inside the DVC, it is necessary to compare the health risk from the composted human excreta to other obvious transmission routes, like children defecating around the household premises etc. Given that a properly operated DVC can reduce helminth egg viability by more than $99 \%$, it is a precondition that the users do not separate urine and fae- 
ces and the farmers operate the DVC properly and only empty one pit at a time and leave the other one untouched.

One limitation of our study was that the excreta were wellmixed, or at least better-mixed than excreta that are typically found in a DVC as a result of the hour-long mixing by shovel. This mixing will more evenly distribute the lime or ash within the excreta and prevent pockets of unmixed excreta that are not exposed to elevated $\mathrm{pH}$. This effect would be expected to increase the inactivation rate in our experiment, as compared to the conditions in a real latrine vault. Therefore our results are not directly transferable to DVC latrines unless they are stirred on a regular basis.

A recent study concluded that the high prevalence of helminth infections in Vietnam are not related to latrine coverage in the population [6]. At a first glance, this study supports our conclusion; however, the study involved a population where $79 \%$ used a single vault latrine and $10 \%$ a DVC. The authors did not stratify between the two latrine types and based their analysis on the farmers' own answer to the question "if they used the excreta as fertilizer". Not surprisingly, only $17 \%$ replied that they used excreta in the fields [6]. This response could be related to the illegal practise of using vault latrines that do not allow stored excreta to be separated from fresh excreta. This also could be the reason why the authors were unable to link the use of fresh excreta from the single pit latrines to the high infection rate in the population. In our study, a similar tendency of significant underreporting was experienced when farmers were questioned about potentially illegal practises [13]. Therefore such questions should be avoided or critically evaluated via triangulation of information techniques.

\section{Conclusion}

Under the climatic conditions existing in the summer months in northern Vietnam, the non-urine diverted Vietnamese Double Vault Composting latrine (DVC) could potentially provide human excreta that is safe to use as fertilizer in agriculture following a storage period of three to four months, if the latrine are stirred on a regular basis. These results are not necessary valid under the colder conditions in the winter months. Different concentrations of lime to increase the $\mathrm{pH}$ were not associated with an increased die-off of A. suum eggs. Free ammonia $\left(\mathrm{NH}_{3}\right)$ is likely to impose a significant negative impact on the survival of Ascaris eggs. If storage times of only three to four months are possible, e.g. because farmers would need to empty the vaults after such short storage, then use of urine diverting latrines should not be recommended. Thus, the non-urine diverted DVC represents a feasible option for farmers in northern Vietnam providing them with a hygi- enic quality of human excreta that can be applied in fields with significantly reduced risks for helminth infections as compared to the direct use from single vault latrines.

\section{List of abbreviations}

$\mathrm{N}$ : Nitrogen; $\mathrm{NH}_{3}$ : Amonia; $\mathrm{NH}_{4}{ }^{+}$: Amonium.

\section{Competing interests}

The authors declare that they have no competing interests.

\section{Authors' contributions}

PKMJ and PDP: Conceived the idea, designed the study and carried out the research in the field.

LTK, FK and AD participated in its design and coordination and helped to draft the manuscript.

All authors read and approved the final manuscript.

\section{Acknowledgements}

We would like to thank the farmers in the study area for facilitating the field work and making this study possible. In Nha Trang are acknowledged The Pasteur Institute, and in Hanoi the National Institute for Soil and Fertilizer Research, and Dr. Hoá at the Friendship Hospital is acknowledged for their support in obtaining helminth eggs for the experiments and for microscopic examination of $A$. suum eggs. Financial support for the study was provided by the Danish International Development Assistance (DANIDA) through projects 91 177; "Sanitary Aspects of Drinking Water and Wastewater Reuse in Vietnam", Grant no. 104.Dan.8.L.; and "Wastewater reuse in agriculture in Vietnam: Water management, environment, and human health aspects". The work of Pham Duc Phuc was supported by the International Foundation of Science (IFS) project number W/3682-I.

\section{References}

I. Phiri K, Whitty CJ, Graham SM, Ssembatya-Lule G: Urban/rural differences in prevalence and risk factors for intestinal helminth infection in southern Malawi. Ann Trop Med Parasitol 2000, 94:38I-387.

2. Hotez PJ, de Silva N, Brooker S, Bethony J: Soil transmitted helminth infections: The nature, causes, and burden of the condition. Fogarty International Centre, National Institute of Health. Maryland. USA. Workingpaper no. 3 Disease Control Priorities Project; 2003.

3. Humphries DL, Stevenson LS, Pearce EJ, The PH, Dan TH, Khanh LT: The use of human faeces for fertilizer is associated with increased intensity of hookworm infection in Vietnamese women. Trans R Soc Trop Med Hyg 1997, 91:518-520.

4. Stephenson LS, Holland CV, Cooper ES: The public health significance of Trichuris trichiura 14. Parasitology 2000, I 2 I (Suppl):S73-S95.

5. Xu LQ, Yu SH, Jiang ZX, Yang JL, Lai LQ, Zhang XJ, Zheng CQ: Soiltransmitted helminthiases: nationwide survey in China 363. Bulletin of the World Health Organization 1995, 73:507-5I3.

6. Yajima A, Jouquet P, Trung DD, Cam TDT, Cong DT, Orange D, Montresor A: High latrine coverage is not reducing the prevalence of soil-transmitted helminthiasis in Hoa Binh province, Vietnam. Transactions of the Royal Society of Tropical Medicine and Hygiene 2009, 103:237-24I.

7. Verle P, Kongs A, De NV, Thieu NQ, Depraetere K, Kim HT, Dorny $P$ : Prevalence of intestinal parasitic infections in northern Vietnam. Trop Med Int Health 2003, 8:96I-964.

8. Hoek W van der, Konradsen F, Cam PD, Hoa ND, Cong LD: Current status of soil-transmitted helminths in Vietnam. The South East Asian Journal of Tropical Medicine and Public Health 2003, 34:I-II. 
9. Phuc DP, Konradsen F, Phuong PT, Cam PD, Dalsgaard D: Practice of using human excreta as fertilizer and implications for health in Nghe An province, Viet Nam. The South East Asian Journal of Tropical Medicine and Public Health 2006, 37:222-229.

10. Knudsen LG, Phuc PD, Hiep NT, Samuelsen H, Jensen PK, Dalsgaard A, Raschid-Sally L, Konradsen F: The fear of awful smell: risk perceptions among farmers in Vietnam using wastewater and human excreta in agriculture. Southeast Asian J Trop Med Public Health 2008, 39:341-352.

II. Water and Sanitation programme: Selling sanitation in Vietnam, what works? Jakarta stock Exchange building, Tower 2, I3th floor, Jl. Jend. Sudirman Kav.52-53, SCBD, Jakarta I2190, Indonesia, Water and sanitation Programme, East Asia and the Pacific; 2002.

12. Government of Vietnam: Decree to ensure clean water and hygiene for rural environment. Decree No. 200/TTg. 1994.

13. Jensen PK, Phuc DP, Knudsen LG, Dalsgaard A, Konradsen F: Hygiene versus fertilizer: The use of human excreta in agriculture - a Vietnamese example. Int J Hyg Environ Health 2008, 21 I(3-4):432-439.

14. Capizzi-Banas S, Deloge M, Remy M, Schwartzbrod J: Liming as an advanced treatment for sludge sanitation: helminth eggs elimination. Water Research 2004, 38:325I-3258.

15. Chien BT, Phi DT, Chung BC, Stenström TA, Carlander A, Westrell $\mathrm{T}$, et al:: Biologicalstudy on retention time of microorganisms in faecal material in urine-diverting eco-san latrines in Vietnam. Vietnam.' Abstract Volume, First International Conference on Ecological Sanitation. 5th-8th November, Nanning, China : I 20- 124.

16. Pecson BM, Nelson KL: Inactivation of Ascaris suum eggs by Ammonia. Environmental Science and Technology 2005 39:7909-79/4.

17. Carlander A, Westrell T: A microbiological and sociological evaluation of urine diverting double-vault latrines in Cam Duc, Vietnam Swedish University of Agricultural Science: Swedish institute for infectious disease control; 1998. Master

18. American public health association: Standard methods for the examination of water and wastewater 20th edition. American public health association; 1998.

19. Kalra YP: Handbook of Reference Methods for Plant Analysis CRC Press; 1998.

20. Polprasert C, Valencia LG: The inactivation of faecal coli forms and Ascaris ova in Faeces by lime. Water Research 1980, | 5:3|-36.

21. Eriksen L, Andreasen P, Ilsøe B: Inactivation of Ascaris suum eggs during storage in lime treated sewage sludge. Water Research 1995, 30:1026-1029.

22. Pecson BM, Barrios JA, Jiménez BE, Nelson KL: The effects of temperature, $\mathrm{pH}$, and ammonia concentration on the inactivation og Ascaris eggs in sewage sludge. Water Research 2007 4I:2893-2902

23. Feachem RG, Bradley DJ, Darelick H, Mara DD: Sanitation and DiseaseHealth aspects of excreta and waste water management John Wiley \& Sons for the World Bank; 1983.

24. Holmqvist A, Stenström TA: Survival of Ascaris suum Ova, Indicator Bacteria and Salmonella Typhimurium Phage 28B in Mesophilic Composting of Household Waste. Ist International Conference on Ecological Sanitation, Nanning China 200I.
Publish with Biomed Central and every scientist can read your work free of charge

"BioMed Central will be the most significant development for disseminating the results of biomedical research in our lifetime. "

Sir Paul Nurse, Cancer Research UK

Your research papers will be:

- available free of charge to the entire biomedical community

- peer reviewed and published immediately upon acceptance

- cited in PubMed and archived on PubMed Central

- yours - you keep the copyright

Submit your manuscript here:

http://www.biomedcentral.com/info/publishing_adv.asp
BioMedcentral 